\title{
Corrigendum: stable matchings and preferences of couples
}

Citation for published version (APA):

Klaus, B. E., Klijn, F., \& Nakamura, T. (2007). Corrigendum: stable matchings and preferences of couples. METEOR, Maastricht University School of Business and Economics. METEOR Research Memorandum No. 025 https://doi.org/10.26481/umamet.2007025

Document status and date:

Published: 01/01/2007

DOI:

10.26481/umamet.2007025

Document Version:

Publisher's PDF, also known as Version of record

\section{Please check the document version of this publication:}

- A submitted manuscript is the version of the article upon submission and before peer-review. There can be important differences between the submitted version and the official published version of record.

People interested in the research are advised to contact the author for the final version of the publication, or visit the DOI to the publisher's website.

- The final author version and the galley proof are versions of the publication after peer review.

- The final published version features the final layout of the paper including the volume, issue and page numbers.

Link to publication

\footnotetext{
General rights rights.

- You may freely distribute the URL identifying the publication in the public portal. please follow below link for the End User Agreement:

www.umlib.nl/taverne-license

Take down policy

If you believe that this document breaches copyright please contact us at:

repository@maastrichtuniversity.nl

providing details and we will investigate your claim.
}

Copyright and moral rights for the publications made accessible in the public portal are retained by the authors and/or other copyright owners and it is a condition of accessing publications that users recognise and abide by the legal requirements associated with these

- Users may download and print one copy of any publication from the public portal for the purpose of private study or research.

- You may not further distribute the material or use it for any profit-making activity or commercial gain

If the publication is distributed under the terms of Article $25 \mathrm{fa}$ of the Dutch Copyright Act, indicated by the "Taverne" license above, 
Bettina Klaus, Flip Klijn, Toshifumi Nakamura

Corrigendum: Stable Matchings and Preferences of Couples

$\mathrm{RM} / 07 / 025$

JEL code: C78, J41

\section{METE@R

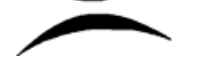

Maastricht research school of Economics

of TEchnology and ORganizations

Universiteit Maastricht

Faculty of Economics and Business Administration

P.O. Box 616

NL - 6200 MD Maastricht

phone : ++31433883830

fax : ++31433884873 



\title{
Corrigendum: Stable Matchings and Preferences of Couples*
}

\author{
Bettina Klaus ${ }^{\dagger} \quad$ Flip Klijn ${ }^{\ddagger} \quad$ Toshifumi Nakamura ${ }^{\S}$
}

June 2007

\begin{abstract}
We correct an omission in the definition of the domain of weakly responsive preferences introduced in Klaus and Klijn (2005) or KK05 for short. The proof of the existence of stable matchings (KK05, Theorem 3.3) and a maximal domain result (KK05, Theorem 3.5) are adjusted accordingly.
\end{abstract}

Keywords: Matching; Couples; Weak Responsiveness; Stability

JEL classification: C78; J41

\section{Two Counter Examples}

The model and notation are as in KK05. The following example demonstrates that the weak responsiveness condition of KK05 is not sufficient to ensure the existence of stable matchings.

KK05's weakly responsive preferences: Couple $c=\left(s_{k}, s_{l}\right)$ has weakly responsive preferences if there exist preferences $\succcurlyeq_{s_{k}}$ and $\succcurlyeq_{s_{l}}$ such that

(i) for all $h \in H$,

$(u, h) \succ_{c}(u, u)$ if and only if $h \succ_{s_{l}} u$ and $(h, u) \succ_{c}(u, u)$ if and only if $h \succ_{s_{k}} u$

(ii) for all $h_{p}, h_{q}, h_{r} \in H \cup\{u\}$,

$\left[h_{p} \succcurlyeq_{s_{k}} u, h_{q} \succcurlyeq_{s_{l}} u\right.$, and $h_{p} \succ_{s_{k}} h_{r}$ imply $\left.\left(h_{p}, h_{q}\right) \succ_{c}\left(h_{r}, h_{q}\right)\right]$ and

$\left[h_{p} \succcurlyeq_{s_{l}} u, h_{q} \succcurlyeq_{s_{k}} u\right.$, and $h_{p} \succ_{s_{l}} h_{r}$ imply $\left.\left(h_{q}, h_{p}\right) \succ_{c}\left(h_{q}, h_{r}\right)\right]$.

Example 1.1 Counter example to KK05's Theorem 3.3 (Existence).

Consider the couples market $\left(P^{H}, P^{C}\right)$ where preferences are given by Table $1 .{ }^{1}$

\begin{tabular}{ccccccc}
\multicolumn{4}{c}{$P^{H}$} & & \multicolumn{2}{c}{$P^{C}$} \\
\cline { 1 - 3 } \cline { 6 - 7 }$h_{1}$ & $h_{2}$ & $h_{3}$ & $h_{4}$ & & $\left(s_{1}, s_{2}\right)$ & $\left(s_{3}, s_{4}\right)$ \\
\hline$s_{1}$ & $s_{3}$ & $s_{1}$ & $s_{3}$ & & $h_{1}, h_{2}$ & $h_{2}, h_{3}$ \\
$s_{4}$ & $s_{2}$ & $s_{4}$ & $s_{2}$ & & $h_{3}, h_{4}$ & $h_{4}, h_{1}$ \\
$\emptyset$ & $\emptyset$ & $\emptyset$ & $\emptyset$ & & $u, u$ & $u, u$ \\
$\ldots$ & $\ldots$ & $\ldots$ & $\ldots$ & & $\ldots$ & $\ldots$
\end{tabular}

Table 1: Couples market 1.1

${ }^{*}$ We thank Fuhito Kojima for useful comments on an earlier version of this corrigendum. B. Klaus thanks the Netherlands Organisation for Scientific Research (NWO) for its support under grant VIDI-452-06-013. F. Klijn's research was supported through the Spanish Plan Nacional I+D+I (SEJ2005-01690) and the Generalitat de Catalunya (SGR2005-00626 and the Barcelona Economics Program of XREA).

${ }^{\dagger}$ Corresponding author. Department of Economics, Maastricht University, P.O. Box 616, 6200 MD Maastricht, The Netherlands, e-mail: B.Klaus@algec.unimaas.nl

${ }^{\ddagger}$ Institut d'Anàlisi Econòmica (CSIC), Campus UAB, 08193 Bellaterra (Barcelona), Spain; e-mail: Flip.Klijn@uab.es

${ }^{\S}$ International Department, Bank of Japan (formerly student at the Faculty of Economics, University of Tokyo), 2-1-1 Nihonbashi-Hongokucho, Chuo-ku, Tokyo, Japan; e-mail: jpbxf676@ybb.ne.jp

${ }^{1}$ An explanation of a real world situation inducing these preferences can be found in Nakamura (2005). 


\begin{tabular}{cccccc} 
matching & $h_{1}$ & $h_{2}$ & $h_{3}$ & $h_{4}$ & blocking coalition \\
\hline 1 & $s_{1}$ & $s_{2}$ & $\emptyset$ & $\emptyset$ & $\left(\left(s_{3}, s_{4}\right),\left(h_{2}, h_{3}\right)\right)$ \\
2 & $\emptyset$ & $s_{3}$ & $s_{4}$ & $\emptyset$ & $\left(\left(s_{1}, s_{2}\right),\left(h_{3}, h_{4}\right)\right)$ \\
3 & $\emptyset$ & $\emptyset$ & $s_{1}$ & $s_{2}$ & $\left(\left(s_{3}, s_{4}\right),\left(h_{4}, h_{1}\right)\right)$ \\
4 & $s_{4}$ & $\emptyset$ & $\emptyset$ & $s_{3}$ & $\left(\left(s_{1}, s_{2}\right),\left(h_{1}, h_{2}\right)\right)$
\end{tabular}

Table 2: Matchings and blocking coalitions

The next two claims prove that this couples market is a counter example to Theorem 3.3 in KK05.

Claim 1. The couples market described in Table 1 has no stable matching.

Let $\mu$ be a matching and $m$ be the number of matched students at $\mu$.

Case $m=0$ : Clearly, $\left(\left(s_{1}, s_{2}\right),\left(h_{1}, h_{2}\right)\right)$ is a blocking coalition for $\mu$.

Case $m=1,3$ : There is a couple with only one matched member. This couple would prefer both its members being unmatched. So, $\mu$ is not individually rational.

Case $m=2$ : If a couple is not matched to one of the two acceptable hospital combinations as specified in Table 1 , then $\mu$ is not individual rational. This leaves us with the four matchings displayed in Table 2, for each of which a blocking coalition for $\mu$ is provided.

Case $m=4:$ By individual rationality, $\left(s_{1}, s_{2}\right)$ is matched to either $\left(h_{1}, h_{2}\right)$ or $\left(h_{3}, h_{4}\right)$ and $\left(s_{3}, s_{4}\right)$ is matched to either $\left(h_{2}, h_{3}\right)$ or $\left(h_{4}, h_{1}\right)$; a contradiction to the feasibility of $\mu$.

Claim 2. The couples' preferences in Table 1 are (KK05-)weakly responsive.

Let $P\left(s_{i}\right)=u, \cdots(i=1,2,3,4)$. We check weak responsiveness conditions (i) and (ii).

(i): For no $c \in C$, there is an $h \in H$ with $(u, h) \succ_{c}(u, u)$ or $(h, u) \succ_{c}(u, u)$. Similarly, for no $s \in S$, there is an $h \in H$ with $h \succ_{s} u$. So, condition (i) is satisfied.

(ii): For each $s \in S$ and each $h \in H, u \succcurlyeq_{s} h$. So, in condition (ii), $h_{p}=u$ and $h_{q}=u$. Since for any $h_{r} \in H,(u, u) \succ_{c}\left(h_{r}, u\right)$ and $(u, u) \succ_{c}\left(u, h_{r}\right)$, condition (ii) is also satisfied.

The next example, which was provided by Fuhito Kojima, demonstrates that based on the definition of couples' weakly responsive preferences only over feasible pairs, not all matchings that are stable in the so-called associated singles market $\left(P^{H}, P^{S}\left(P^{C}\right)\right)$ need to be stable for the original couples market $\left(P^{H}, P^{C}\right)$.

Example 1.2 Counter example to KK05's Theorem 3.3 (Stability).

Consider the couples market $\left(P^{H}, P^{C}\right)$ and the associated singles market $\left(P^{H}, P^{S}\left(P^{C}\right)\right)$ where preferences are given by Table 3 .

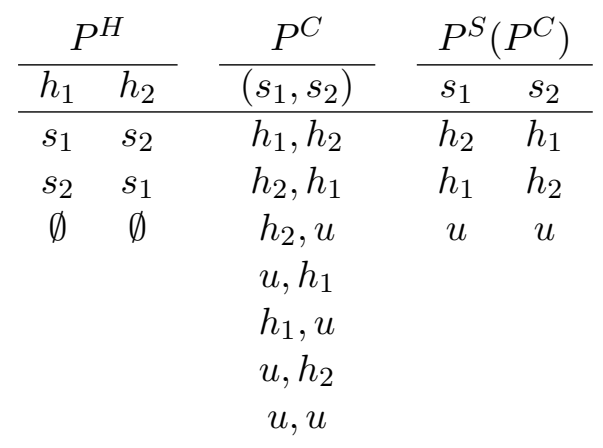

Table 3: Couples market 1.2 
It is easy to check that the associated singles market $\left(P^{H}, P^{S}\left(P^{C}\right)\right)$ has two stable matchings, namely $\mu(S)=h_{1}, h_{2}$ and $\mu^{\prime}(S)=h_{2}, h_{1}$. However, $\mu^{\prime}$ is not stable for the original couples market $\left(P^{H}, P^{C}\right)$.

\section{Corrections: Weak Responsiveness and Domain Maximality}

Theorems 3.3 and 3.5 in KK05 are affected by the omission in the definition of weak responsiveness that Example 1.1 illustrates. We now formulate a weak additional condition that is in line with KK05's intuitive motivation and description of weak responsiveness.

The driving force behind Example 1.1 is that for a couple two individually undesirable positions can be combined to a desirable allotment. To exclude this possibility, we add condition (iii) to KK05's definition of weak responsiveness.

Weakly responsive preferences, condition (iii):

(iii) for all $h^{\prime}, h^{\prime \prime} \in H, h^{\prime} \neq h^{\prime \prime}, u \succ_{s_{k}} h^{\prime}$ and $u \succ_{s_{l}} h^{\prime \prime}$ imply $(u, u) \succ_{c}\left(h^{\prime}, h^{\prime \prime}\right)$.

KK05 (page 82, lines 9-12) motivated weak responsiveness as follows: "The idea of this extension [i.e., from responsiveness to weak responsiveness] is that the exact associated preferences that deal with the comparison of unacceptable positions are irrelevant with respect to stability since an agent can always replace any unacceptable position with unemployment." Without condition (iii), the only case where the agents in a couple may not want to replace their unacceptable positions by unemployment occurs when the combination of them is acceptable - a case that is now excluded by (iii). We would like to emphasize that since condition (iii) is still in line with the intuition that motivated weak responsiveness, we do not find it necessary to change the nomenclature. The corrected weak responsiveness is logically equivalent to Nakamura's (2005) "reasonable responsiveness" condition.

The driving force behind Example 1.2 is that even though $h_{2}$ is student $s_{1}$ 's individually best hospital and $h_{1}$ is student $s_{2}$ 's individually best hospital, as a couple $\left(s_{1}, s_{2}\right)$ prefers $\left(h_{1}, h_{2}\right)$ to $\left(h_{2}, h_{1}\right)$. One reason why the couples' preferences in Example 1.2 are weakly responsive is that we have defined couples' preferences only over ordered pairs of different hospitals.

One way to deal with the pathological character of Example 1.2 is to drop the feasibility constraint in the definition of couples' preferences, i.e., to assume that couples' preferences include entries of the form $(h, h), h \in H$. Then, the couples' preferences in Example 1.2 are no longer weakly responsive (we would have $\left.\left(h_{2}, h_{1}\right) \succ_{c}\left(h_{1}, h_{1}\right) \succ_{c}\left(h_{1}, h_{2}\right)\right){ }^{2}$ The drawback of this correction is that then the proof of another result is affected and cannot easily be restored. ${ }^{3}$

Alternatively, we can relax the statement of KK05's Theorem 3.3 as follows.

KK05's Theorem 3.3 (Stability for weakly responsive preferences)

Let $\left(P^{H}, P^{C}\right)$ be a couples market where couples have weakly responsive preferences. Then, any matching that is stable for an associated singles market $\left(P^{H}, P^{S}\left(P^{C}\right)\right)$ induces ${ }^{4}$ a stable matching for $\left(P^{H}, P^{C}\right)$. In particular, there exists a stable matching for $\left(P^{H}, P^{C}\right)$.

Proof. The first 13 lines of the proof are identical to the proof of Theorem 3.3 in KK05. Then the next two lines should be adjusted as follows (the change is marked in bold face). "Assume $h_{p} \prec_{s_{k}} u$ and $h_{q} \prec_{s_{l}} u$. Then by weak responsiveness (iii), $(\mathbf{u}, \mathbf{u}) \succ_{\mathbf{c}}\left(\mathbf{h}_{\mathbf{p}}, \mathbf{h}_{\mathbf{q}}\right)$. Using ..." The proof continues now as in KK05 until the end of page 83. We then continue as follows.

\footnotetext{
${ }^{2}$ Note that with this correction line 1 on page 84 in KK05's proof of Theorem 3.3 would be correct since with our correction $\left(h_{p}, \mu\left(s_{l}\right)\right)$ is also a part of the couples' preferences if $h_{p}=\mu\left(s_{l}\right)$.

${ }^{3}$ The construction in our proof of KK05's Theorem 3.5 that we present later will not work, e.g., in Cases 2.2 and 2.3 , the entry $\left(h_{r}, h_{q}\right)$ with $h_{r}=h_{q}$ would be problematic.

${ }^{4}$ That is, any matching $\mu$ that is stable for $\left(P^{H}, P^{S}\left(P^{C}\right)\right)$ either is also stable for $\left(P^{H}, P^{C}\right)$ or a stable matching for $\left(P^{H}, P^{C}\right)$ can be easily obtained from $\mu$ as explained in the proof.
} 
If $h_{p} \neq \mu\left(s_{l}\right)$, then weak responsiveness (ii) implies $\left(\mu\left(s_{k}\right), \mu\left(s_{l}\right)\right) \succeq_{c}\left(h_{p}, \mu\left(s_{l}\right)\right) \succeq_{c}\left(h_{p}, h_{q}\right)$, which contradicts (b1). If $h_{q} \neq \mu\left(s_{k}\right)$, then similarly we obtain a contradiction to (b2). Note that the only case for which the last argument does not apply is the case where $h_{p}=\mu\left(s_{l}\right)$ and $h_{q}=\mu\left(s_{k}\right)$. In other words, all blocking coalitions are of the form $\left(\left(s_{k}, s_{l}\right),\left(\mu\left(s_{l}\right), \mu\left(s_{k}\right)\right)\right)$. Then we can easily obtain a stable matching $\mu^{\prime}$ from $\mu$ by satisfying all these blocking coalitions, i.e., for all couples $\left(s_{k}, s_{l}\right)$ involved in a blocking coalition, $\mu^{\prime}\left(s_{k}\right)=\mu\left(s_{l}\right)$ and $\mu^{\prime}\left(s_{l}\right)=\mu\left(s_{k}\right)$.

Next, we state KK05's Theorem 3.5 and provide a completely new and more accessible proof (an alternative proof can be found in Nakamura, 2005).

KK05's Theorem 3.5 (Maximal Domain I)

For couples markets with restricted strictly unemployment averse couples, the domain of weakly responsive preferences is a maximal domain for the existence of stable matchings.

Proof. Let $c_{1}=\left(s_{1}, s_{2}\right)$ and $\succcurlyeq_{c_{1}}$ be such that $c_{1}$ 's preferences are restricted strictly unemployment averse, but not weakly responsive.

Consider students' preferences $\succcurlyeq_{s_{1}}$ and $\succcurlyeq_{s_{2}}$ defined such that for all $h, h^{\prime} \in H \cup\{u\},\left[h \succcurlyeq_{s_{1}} h^{\prime}\right.$ if and only if $\left.(h, u) \succcurlyeq_{c_{1}}\left(h^{\prime}, u\right)\right]$ and $\left[h \succcurlyeq_{s_{2}} h^{\prime}\right.$ if and only if $\left.(u, h) \succcurlyeq_{c_{1}}\left(u, h^{\prime}\right)\right]$. In particular, preferences $\succcurlyeq_{s_{1}}, \succcurlyeq_{s_{2}}$, and $\succcurlyeq_{c_{1}}$ satisfy (i).

Couple $c_{1}$ 's preferences not being responsive means that there do not exist students' preferences that satisfy conditions (i), (ii), and (iii). Thus, $\succcurlyeq_{s_{1}}$ and $\succcurlyeq_{s_{2}}$ as defined above, together with $\succcurlyeq_{c_{1}}$, violate condition (ii) or (iii). For each possible violation of (ii) or (iii) we either show that it is incompatible with restricted strict unemployment aversion or we construct preferences of the hospitals and restricted strictly unemployment averse and weakly responsive preferences of the other couples such that no stable matching exists.

Case 1. Assume that $\succcurlyeq_{s_{1}}, \succcurlyeq_{s_{2}}$, and $\succcurlyeq_{c_{1}}$ violate condition (iii).

Then, there exist $h^{\prime}, h^{\prime \prime} \in H, h^{\prime} \neq h^{\prime \prime}$, such that $u \succ_{s_{1}} h^{\prime}, u \succ_{s_{2}} h^{\prime \prime}$, and $\left(h^{\prime}, h^{\prime \prime}\right) \succ_{c_{1}}(u, u)$. Thus, by the definition of $\succcurlyeq_{s_{1}}$ and $\succcurlyeq_{s_{2}},(u, u) \succ_{c_{1}}\left(h^{\prime}, u\right)$ and $(u, u) \succ_{c_{1}}\left(u, h^{\prime \prime}\right)$.

Now, for $h^{\prime}, h^{\prime \prime}$ and $h \in H \backslash\left\{h^{\prime}, h^{\prime \prime}\right\}$ we specify $P\left(h^{\prime}\right)=s_{1}, s_{3}, \emptyset, \ldots, P\left(h^{\prime \prime}\right)=s_{3}, s_{2}, \emptyset, \ldots$, and $P(h)=\emptyset, \ldots$. Couple $c_{2}=\left(s_{3}, s_{4}\right)$ has restricted strictly unemployment averse responsive preferences based on $P\left(s_{3}\right)=h^{\prime}, h^{\prime \prime}, u, \ldots$ and $P\left(s_{4}\right)=u, \ldots$ Note that for any individually rational matching $\mu, \mu\left(c_{2}\right) \in\left\{\left(h^{\prime}, u\right),\left(h^{\prime \prime}, u\right),(u, u)\right\}$. Assume that $\mu$ is stable. Then, $\mu\left(c_{1}\right) \in$ $\left\{\left(h^{\prime}, h^{\prime \prime}\right),(u, u)\right\}$. If $\mu\left(c_{2}\right)=(u, u)$, then $\mu$ is be blocked by $\left(c_{2},\left(h^{\prime \prime}, u\right)\right)$. If $\mu\left(c_{2}\right)=\left(h^{\prime \prime}, u\right)$, then $\mu\left(c_{1}\right)=(u, u)$. Hence, $\mu$ is blocked by $\left(c_{2},\left(h^{\prime}, u\right)\right)$. If $\mu\left(c_{2}\right)=\left(h^{\prime}, u\right)$, then $\mu$ is blocked by $\left(c_{1},\left(h^{\prime}, h^{\prime \prime}\right)\right)$. Thus all candidates for a stable matching are blocked.

Case 2. Assume that $\succcurlyeq_{s_{1}}, \succcurlyeq_{s_{2}}$, and $\succcurlyeq_{c_{1}}$ violate condition (ii). We split condition (ii) into subconditions:

(iia) Condition (ii) for $h_{r}=u$ : for all $h_{p}, h_{q} \in H \cup\{u\}$,

(iia.1) $\left[h_{p} \succ_{s_{1}} u\right.$ and $h_{q} \succcurlyeq_{s_{2}} u$ imply $\left.\left(h_{p}, h_{q}\right) \succ_{c_{1}}\left(u, h_{q}\right)\right]$ and

(iia.2) $\left[h_{p} \succ_{s_{2}} u\right.$ and $h_{q} \succcurlyeq_{s_{1}} u$ imply $\left.\left(h_{q}, h_{p}\right) \succ_{c_{1}}\left(h_{q}, u\right)\right]$,

(iib) Condition (ii) for $u \succ_{s_{1}} h_{r}$ : for all $h_{p}, h_{q}, h_{r} \in H \cup\{u\}$,

(iib.1) $\left[h_{p} \succcurlyeq_{s_{1}} u \succ_{s_{1}} h_{r}\right.$ and $h_{q} \succcurlyeq_{s_{2}} u$ imply $\left.\left(h_{p}, h_{q}\right) \succ_{c_{1}}\left(h_{r}, h_{q}\right)\right]$ and

(iib.2) $\left[h_{p} \succcurlyeq_{s_{2}} u \succ_{s_{2}} h_{r}\right.$ and $h_{q} \succcurlyeq_{s_{1}} u$ imply $\left.\left(h_{q}, h_{p}\right) \succ_{c_{1}}\left(h_{q}, h_{r}\right)\right]$,

(iic) Condition (ii) for $h_{r} \succ_{s_{1}} u$ : for all $h_{p}, h_{q}, h_{r} \in H \cup\{u\}$,

(iic.1) $\left[h_{p} \succ_{s_{1}} h_{r} \succ_{s_{1}} u\right.$ and $h_{q} \succcurlyeq_{s_{2}} u$ imply $\left.\left(h_{p}, h_{q}\right) \succ_{c_{1}}\left(h_{r}, h_{q}\right)\right]$ and

(iic.2) $\left[h_{p} \succ_{s_{2}} h_{r} \succ_{s_{2}} u\right.$ and $h_{q} \succcurlyeq_{s_{1}} u$ imply $\left.\left(h_{q}, h_{p}\right) \succ_{c_{1}}\left(h_{q}, h_{r}\right)\right]$.

Case 2.1. Restricted strict unemployment aversion implies (iia).

(iia.1): Consider $h_{p} \succ_{s_{1}} u$ and $h_{q} \succcurlyeq_{s_{2}} u$. Thus, by the definition of $\succcurlyeq_{s_{1}}$ and $\succcurlyeq_{s_{2}},\left(h_{p}, u\right) \succ_{c_{1}}(u, u)$ and $\left(u, h_{q}\right) \succcurlyeq_{c_{1}}(u, u)$. If $h_{q}=u$, then $\left(h_{p}, u\right) \succ_{c_{1}}(u, u)$ implies (iia.1). If $h_{q} \neq u$, then $h_{q} \succ_{s_{2}} u$ and, 
by the definition of $\succcurlyeq_{s_{2}},\left(u, h_{q}\right) \succ_{c_{1}}(u, u)$. Hence, by restricted strict unemployment aversion, $\left(h_{p}, h_{q}\right) \succ_{c_{1}}\left(u, h_{q}\right)$ and (iia.1) holds. The proof for (iia.2) is similar.

Case 2.2. Assume that $\succcurlyeq_{s_{1}}, \succcurlyeq_{s_{2}}$, and $\succcurlyeq_{c_{1}}$ violate condition (iib).

(iib.1): Consider $h_{p} \succcurlyeq_{s_{1}} u \succ_{s_{1}} h_{r}$ and $h_{q} \succcurlyeq_{s_{2}} u$. Thus, by the definition of $\succcurlyeq_{s_{1}}$ and $\succcurlyeq_{s_{2}}$, $\left(h_{p}, u\right) \succcurlyeq_{c_{1}}(u, u) \succ_{c_{1}}\left(h_{r}, u\right)$ and $\left(u, h_{q}\right) \succcurlyeq_{c_{1}}(u, u)$. If $h_{q}=u$, then $\left(h_{p}, u\right) \succ_{c_{1}}\left(h_{r}, u\right)$ implies (iib.1). Thus, let $h_{q} \neq u$ and assume, in contradiction to (iib.1), $\left(h_{r}, h_{q}\right) \succ_{c_{1}}\left(h_{p}, h_{q}\right)$. By restricted strict unemployment aversion, $\left(h_{p}, h_{q}\right) \succcurlyeq_{c_{1}}\left(u, h_{q}\right) \succ_{c_{1}}(u, u)$. Thus, $\left(h_{r}, h_{q}\right) \succ_{c_{1}}\left(u, h_{q}\right) \succ_{c_{1}}(u, u)$.

For $h_{r}, h_{q} \in H$ and $h \in H \backslash\left\{h_{r}, h_{q}\right\}$ we specify $P\left(h_{r}\right)=s_{1}, s_{3}, \emptyset, \ldots, P\left(h_{q}\right)=s_{3}, s_{2}, \emptyset, \ldots$, and $P(h)=\emptyset, \ldots$. Couple $c_{2}=\left(s_{3}, s_{4}\right)$ has restricted strictly unemployment averse responsive preferences based on $P\left(s_{3}\right)=h_{r}, h_{q}, u, \ldots$ and $P\left(s_{4}\right)=u, \ldots$ For any individually rational matching $\mu, \mu\left(c_{2}\right) \in\left\{\left(h_{r}, u\right),\left(h_{q}, u\right),(u, u)\right\}$. Assume that $\mu$ is stable. If $\mu\left(c_{2}\right)=(u, u)$, then $\mu$ is blocked by $\left(c_{2},\left(h_{q}, u\right)\right)$. If $\mu\left(c_{2}\right)=\left(h_{r}, u\right)$, then by individual rationality, $\mu\left(c_{1}\right) \in\left\{(u, u),\left(u, h_{q}\right)\right\}$. Hence, $\mu$ is blocked by $\left(c_{1},\left(h_{r}, h_{q}\right)\right)$. If $\mu\left(c_{2}\right)=\left(h_{q}, u\right)$, then by individual rationality, $\mu\left(c_{1}\right)=$ $(u, u)$. Hence, $\mu$ is blocked by $\left(c_{2},\left(h_{r}, u\right)\right)$. Thus all candidates for a stable matching are blocked. The proof for (iib.2) is similar.

Case 2.3. Assume that $\succcurlyeq_{s_{1}}, \succcurlyeq_{s_{2}}$, and $\succcurlyeq_{c_{1}}$ violate condition (iic).

(iic.1): Consider $h_{p} \succ_{s_{1}} h_{r} \succ_{s_{1}} u$ and $h_{q} \succcurlyeq_{s_{2}} u$. Thus, by the definition of $\succcurlyeq_{s_{1}}$ and $\succcurlyeq_{s_{2}}$, $\left(h_{p}, u\right) \succ_{c_{1}}\left(h_{r}, u\right) \succ_{s_{1}}(u, u)$ and $\left(u, h_{q}\right) \succcurlyeq_{s_{2}}(u, u)$. If $h_{q}=u$, then $\left(h_{p}, u\right) \succ_{c_{1}}\left(h_{r}, u\right)$ implies (iic.1). Thus, let $h_{q} \neq u$ and assume, in contradiction to (iic.1), $\left(h_{r}, h_{q}\right) \succ_{c_{1}}\left(h_{p}, h_{q}\right)$. By restricted strict unemployment aversion, $\left(h_{p}, h_{q}\right) \succ_{c_{1}}\left(h_{p}, u\right) \succ_{c_{1}}(u, u)$ and $\left(h_{p}, h_{q}\right) \succ_{c_{1}}\left(u, h_{q}\right) \succ_{c_{1}}(u, u)$. Thus, $\left(h_{r}, h_{q}\right) \succ_{c_{1}}\left(h_{p}, h_{q}\right) \succ_{c_{1}}(u, u),\left(h_{r}, h_{q}\right) \succ_{c_{1}}\left(h_{p}, u\right)$, and $\left(h_{r}, h_{q}\right) \succ_{c_{1}}\left(u, h_{q}\right)$.

For $h_{p}, h_{r}, h_{q} \in H$ and $h \in H \backslash\left\{h_{p}, h_{r}, h_{q}\right\}$ we specify $P\left(h_{p}\right)=s_{1}, \emptyset, \ldots, P\left(h_{r}\right)=s_{1}, s_{3}, \emptyset, \ldots$, $P\left(h_{q}\right)=s_{3}, s_{2}, \emptyset, \ldots$, and $P(h)=\emptyset, \ldots$. Couple $c_{2}=\left(s_{3}, s_{4}\right)$ has restricted strictly unemployment averse responsive preferences based on $P\left(s_{3}\right)=h_{r}, h_{q}, u, \ldots$ and $P\left(s_{4}\right)=u, \ldots$ For any individually rational matching $\mu, \mu\left(c_{2}\right) \in\left\{\left(h_{r}, u\right),\left(h_{q}, u\right),(u, u)\right\}$. Assume that $\mu$ is stable. If $\mu\left(c_{2}\right)=(u, u)$, then $\mu$ is blocked by $\left(c_{2},\left(h_{q}, u\right)\right)$. If $\mu\left(c_{2}\right)=\left(h_{r}, u\right)$, then by individual rationality, $\left.\mu\left(c_{1}\right) \in\left\{\left(h_{p}, h_{q}\right),\left(h_{p}, u\right)\right),\left(u, h_{q}\right),(u, u)\right\}$. Hence, $\mu$ is blocked by $\left(c_{1},\left(h_{r}, h_{q}\right)\right)$.

If $\mu\left(c_{2}\right)=\left(h_{q}, u\right)$, then by individual rationality, $\mu\left(c_{1}\right) \in\left\{\left(h_{p}, u\right),\left(h_{r}, u\right),(u, u)\right\}$. If $\mu\left(c_{1}\right) \in$ $\left\{\left(h_{p}, u\right),(u, u)\right\}$, then $\mu$ is blocked by $\left(c_{2},\left(h_{r}, u\right)\right)$. If $\mu\left(c_{1}\right)=\left(h_{r}, u\right)$, then $\mu$ is blocked by $\left(c_{1},\left(h_{p}, u\right)\right)$. Thus all candidates for a stable matching are blocked. The proof for (iic.2) is similar.

\section{References}

[1] B. Klaus and F. Klijn, Stable matchings and preferences of couples, Journal of Economic Theory 121 (2005), 75-106.

[2] T. Nakamura, A simple example of instability and a new condition for stability in matching with couples, Graduate School of Economics, University of Tokyo, Discussion Paper COEF-70 (2005). 